\title{
Eye Movements in Reading: Models and Data
}

\author{
Keith Rayner \\ Department of Psychology \\ University of California, San Diego
}

\begin{abstract}
Models of eye movement control in reading and their impact on the field are discussed. Differences between the E-Z Reader model and the SWIFT model are reviewed, as are benchmark data that need to be accounted for by any model of eye movement control. Predictions made by the models and how models can sometimes account for counterintuitive findings are also discussed. Finally, the role of models and data in further understanding the reading process is considered.
\end{abstract}

Keywords: Reading, Eye Movements, Models of Eye Movements.

The study of eye movements during reading has a long and rich history dating back to the latter part of the 19th century. Elsewhere, I (Rayner, 1978, 1998) have argued that there have been three eras of research on eye movements during reading. But, it now is apparent that we have entered a new, fourth, era in which sophisticated computational models of eye movement control are dominating the field. Given this new trend, it is perhaps appropriate to consider exactly what role these models, in contrast to empirical data from experimental manipulations and corpus-based analyses, should play in furthering our understanding of the reading process.

The first era extended from Javal's initial observations concerning the role of eye movements during reading (see Huey, 1908) until about 1920. During this first era, many of the basic facts about eye movements during reading were discovered. In addition, issues such as the perceptual span (the region of effective vision), saccade latency (the time it takes to initiate an eye movement), and saccadic suppression (the fact that we do not perceive information during an eye movements) were of central interest.

The second era, which coincided with the behaviorist movement in experimental psychology, tended to

This article is based on the keynote address delivered by the author at the Fourteenth European Conference on Eye Movements at Potsdam, Germany in August 2007. A version of the talk was also presented at the International Congress of Psychology at Berlin, Germany in July, 2008. Thanks to Reinhold Kliegl, Simon P. Liversedge, Erik D. Reichle, and an anonymous reviewer for comments on a prior draft.

Correspondence to Keith Rayner, Department of Psychology, University of California, San Diego, La Jolla, CA 92093. deal with more surface properties of eye movements, and little attempt was made to infer mental processes from eye movement data. Classic work by Tinker (1946) on reading and by Buswell (1935) on scene perception was carried out during this era. Tinker's (1958) final review ended on the rather pessimistic note that almost everything that had been learned about reading via eye movements (given the technology of the time) had been discovered. As I remarked earlier (Rayner, 1998), this opinion seems to have been widely held because very little research on eye movements during reading was undertaken between the late 1950's and the mid-1970's.

The third era began in the mid-1970's and was marked by both a better description of language and rapid technological advances that resulted in marked improvements in eye movement recording systems (and computer systems) that allowed measurements to be more accurate and more easily obtained. These advances in technology also made possible the development of innovative techniques in which the visual display could be changed contingent on the eye position. In this gaze-contingent display change paradigm (McConkie \& Rayner, 1975; Rayner, 1975; Reder, 1973), eye movements are monitored and changes are made in the visual display that the reader is looking at contingent on when the eyes move (or at some other time during the fixation). During this third era, great strides were made as a result of researchers designing interesting and informative studies using gaze contingent change (as well as other) techniques.

As noted at the outset of this article, it is now fairly obvious that we have entered a fourth era of research on eye movements during reading, beginning in the late 1990's, characterized by the development of complex and sophisticated models (in the form of implemented computer simulations). Much of the research on eye movements during reading over the past ten years has been focused on either providing validity for 
or disconfirming these models. Table 1 provides a list of the currently implemented models. Some might argue that the model provided by Just and Carpenter (1980; see Thibadeau, Just, \& Carpenter, 1982 for actual simulations) was the first such model, and I wouldn't argue with such a claim. However, it also seems fairly clear that the E-Z Reader model was the impetus for the development of the competing models listed in Table 1. Although not the first such model (as Mr. Chips preceded it by a year), E-Z Reader has arguably attracted the most attention, largely because of the transparency of the model, the clear predictions that it makes, and the fact that it accounts for a tremendous amount of eye movement data. SWIFT is generally regarded as the main competitor to E-Z Reader ${ }^{1}$

In this article, I will primarily use E-Z Reader as the context for various points to be made (though I will also discuss SWIFT as a contrast point). At a conference in Tianjin, China in 2006, Reinhold Kliegl (one of the architects, along with Ralf Engbert, of the SWIFT model) made the following provocative claim: "Models of eye movement control in reading are more sophisticated and realistic than models in any other area of psychology". Undoubtedly there are many who would dispute this claim because there are highly sophisticated models (generally implemented) in many areas of psychology (especially cognitive psychology), yet his claim has special force when one considers his additional proviso concerning being "realistic". Virtually all of the eye movement models produce data that fit directly with the human data. That is, the models produce eye fixations durations in milliseconds (and not number of processing cycles or some other more indirect metric) and they likewise produce number of fixations, saccade length, skipping rates, and so on. The predictions made by the models are also in terms of real units (words) rather than regions of interest.

My goal in the present article is threefold. First, I will discuss the data that models of eye movement control in reading should be able to handle. Second, I will summarize some predictions that follow from E-Z Reader and SWIFT and point out how they can provide accounts of what otherwise might be difficult data to explain (as well as discuss how the models have been changed and extended). Third, I will argue that models and data should go hand-in-hand to further our understanding of reading. Prior to discussing these issues, a brief overview of E-Z Reader will be provided, as well as some comments on what distinguishes the models.

\section{The E-Z Reader Model}

The details of E-Z Reader have been presented elsewhere and here I will only provide a brief and cursory overview. In actuality, E-Z Reader is a family of models with the first five versions discussed in Reichle, Pollatsek, Fisher, and Rayner (1998) and subsequent versions presented by Reichle, Rayner, and Pollatsek
(2003), Rayner, Ashby, Reichle, and Pollatsek (2004), and Pollatsek, Reichle, and Rayner (2006). In all of these versions of the model, lexical processing is the engine that drives eye movements during reading. The most recent version of the model, E-Z Reader 10 (Reichle, Warren, \& O'Connell, 2009) presents an attempt to include the influence of higher order variables on eye movements during reading. The model has also been extended to Chinese readers (Rayner, Li, \& Pollatsek, 2007) and older readers (Rayner, Reichle, Stroud, Williams, \& Pollatsek, 2006).

According to E-Z Reader, two stages of lexical processing are underway when readers fixate a word. An initial stage, referred to as L1, can be characterized as the system determining if it is likely to know what the fixated word is in the next few milliseconds. Once a certain threshold is exceeded, a signal is sent to the oculomotor system to program a saccade to the next unidentified word in the text. This decision of where to go next is also influenced by a low level attentional scan operating in parallel with lexical processing that is more or less surveying the terrain of what is coming up (and where word boundaries are). The second stage of lexical processing, L2, is akin to lexical access for the word. When L2 completes, attention moves to word $n+1$, and the two stages begin running for that word. On some occasions, L1 and L2 will both complete for word $n+1$ (such as when it is a highly predictable word) and attention will shift to word $n+2$; the saccade to word $n+1$ will also be cancelled and a saccade programmed to word $n+2$ (provided that the prior saccade program has not passed a point of no return). Given that the two stages are influenced by the frequency and predictability of word n, lexical processing is the engine driving the eyes through the text according to E-Z Reader.

\section{How Do the Models Differ?}

It is generally recognized that there are two primary ways in which the various models differ (see Reichle et al., 2003 for a more extended discussion). Here, I'll focus on how E-Z Reader and SWIFT differ. First, E-Z Reader has been categorized as a serial attention shift (SAS) model, whereas SWIFT has been categorized as a gradient by attention guidance $(G A G)^{2}$ model. The main distinction is that in E-Z Reader serial lexical processing (word $n$ is identified then word $n+1$ and then word $n+2$, in order) is invoked whereas in SWIFT parallel lexical processing is possible (so that more than one word can be processed lexically at any given point in an eye fixation). There has been considerable discussion about this issue lately (see Kennedy \& Pynte,

${ }^{1}$ With all due apologies to the designers of the other models listed in Table 1 for the possible ego-centric nature of this claim.

${ }^{2}$ Chuck Clifton recently pointed out that E-Z Reader wins out if one simply goes by better sounding or more appealing acronyms. 
Table 1

Models of Eye Movement Control in Reading. The type of model is in parentheses behind the name of the model. Model Key References

E-Z Reader (SAS)

Reichle, Pollatsek, Fisher, \& Rayner, 1998

Reichle, Rayner, \& Pollatsek, 2003

Pollatsek, Reichle, \& Rayner, 2006

SWIFT (GAG)

Engbert, Longtin, \& Kliegl, 2002

Engbert, Nuthmann, Richter, \& Kliegl, 2005

Mr. Chips (Ideal Observer ${ }^{a}$ )

Legge, Klitz, \& Tjan, 1997

Legge, Hooven, Klitz, Mansfield, \& Tjan, 2002

EMMA (SAS within ACT system)

Salvucci, 2001

Glenmore (GAG within Connectionist System)

Reilly \& Radach, 2006

SERIF $\left(\mathrm{POC}^{b}\right)$

McDonald, Carpenter, \& Shillcock, 2005

Competition/Activation (POC)

Yang \& McConkie, 2001

Yang, 2006

SHARE (POC)

Feng, 2006

${ }^{a}$ Ideal Observer models do not attempt to mimic human reading.

${ }^{b}$ In POC (Primarily Oculomotor Control) models, most of the variation in eye fixation times is due to properties of the oculomotor system, and lexical variables only influence very long fixations. There is some variation across the models in terms of how early in a fixation lexical processing can affect the duration of the current fixation. In SERIF, perceptual processing of words has a more immediate effect on when they eyes move than in the Competition/Activation model or SHARE.

2006, 2008; Kliegl, 2007; Kliegl, Nuthmann, \& Engbert, 2006; Rayner, Reichle, Drieghe, Slattery, \& Pollatsek, 2007; Rayner, Pollatsek, Liversedge, \& Reichle, 2009; Reichle, Liversedge, Pollatsek, \& Rayner, 2009) and no clear consensus has yet emerged. However, it may be fair to say that, in principle, much (or perhaps some) of the time GAG models function as serial models, though the advocates of GAG models would also claim that there are existence proofs that more one than word can be processed at once.

The second way in which the models differ relates to the influence of cognitive/lexical properties of the fixated word on how long readers remain on that word. In E-Z Reader, as noted above, cognitive/lexical processes are the engine that drives the eyes through the text; in SWIFT, saccades are autonomously generated but with occasional cognitive influences. Both models thus allow for the influence of variables like word frequency and word predictability on fixation times and both models allow for the early influence of such vari- ables. On the other hand, some models (such as the Competition Inhibition model) generally posit that cognitive/lexical variables can only have an effect on eye movements very late in an eye fixation. In my view, there are rather striking data (to be discussed below) that render this claim fairly implausible.

\section{Benchmark Data}

Valid models need to account for what is known about the basic properties of eye movements during reading. There are five central facts that any model needs to account for (see Rayner, 1998, 2009 for reviews). First, the average fixation duration in reading is about $200-250 \mathrm{~ms}$ (though there is considerable variability with some fixations under $100 \mathrm{~ms}$ and some over $500 \mathrm{~ms}$ ). Second, the average saccade length (for alphabetic writing systems) is about 7-9 letter spaces (again with considerable variability as some saccades are less than 1 letter space and some are as long as 
over 20 letter spaces). Third, various measures of processing time, such as first fixation duration (the duration of the first fixation on a word), single fixation duration (the duration of the fixation when only one fixation is made on a word), and gaze duration (the sum of all fixations on a word prior to moving to another word) are sensitive to certain properties of the fixated word (to be discussed below). Fourth, readers skip (do not directly fixate) about $25-30 \%$ of words in text (with word length strongly influencing skipping rates as short words are skipped much more than long words; word predictability and word frequency, to a lesser extent, also influence skipping rates). Fifth, readers make regressions (saccades backwards to look at words that occurred earlier in the text) about $10-15 \%$ of the time. Many of the implemented models are able to account for these findings (though in many cases, some of them are hard-wired in the model). The most problematic issue for most models with respect to the above facts is that they do not do a particularly good of a job in accounting for regressions ${ }^{3}$. This is perhaps because it is quite difficult for researchers to control when readers regress (as well as when they skip words).

In addition, five other findings are generally agreed upon as being valid characteristics of eye movements in reading (see Rayner, 1998, 2009), and hence, need to be accounted for by models of eye movement control. First, the perceptual span (or region of effective vision during a fixation) extends 3-4 letter spaces to the left of fixation to 14-15 letter spaces to the right of fixation. Second, readers obtain useful preview benefit from the word to the right of fixation; evidence for this finding comes from numerous studies using the boundary paradigm (Rayner, 1975) in which a preview word changes to a target word during a saccade. It is generally accepted that the source of the preview benefit effect is from orthographic, phonological, and abstract letter codes. Interestingly, semantic preview benefit is not obtained in English; thus, a semantically related word like song as a preview for tune doesn't provide preview benefit (Altarriba, Kambe, Pollatsek, \& Rayner, 2001; Rayner, Balota, \& Pollatsek, 1986). Third, the amount of time that readers look at words varies as a function of variables such as word frequency and word predictability. Indeed, the fact that first fixation durations on a word are influenced by lexical variables, in my opinion, renders models that do not allow for such early effects quite implausible and such models are seriously compromised by these findings 4 Fourth, there are effects associated with the launch site of a saccade and the landing position of the saccade (McConkie, Kerr, Reddix, \& Zola, 1988; Rayner, 1979). Specifically, readers tend to fixate about halfway between the beginning of a word and the middle of the word (Rayner, 1979). Fifth, somewhat paradoxically, single fixation durations are longer when the eyes land in the middle of a word, the Inverted Optimal View- ing Position (IOVP) effect; Vitu, McConkie, Kerr, \& O'Regan, 2001) than when they land on the end letters of a word (though frequency effects remain constant). Once again, the models do a fairly good job of accounting for these effects $5^{5}$ (again, with some of the effects hard-wired in the model).

\section{Predictions from the Models}

Models are generally evaluated, not only for how well they handle benchmark data, but also by how effectively they make unique predictions. Both E-Z Reader and SWIFT make unique predictions. Four such predictions will be discussed here. First, E-Z Reader predicts that when readers skip a word, the fixation prior to the skip (and to a lesser degree, the fixation after the skip) should be inflated. This prediction flows from the central assumption in E-Z Reader that words are lexically identified in a serial fashion. On this issue, the data are somewhat mixed as some studies (Rayner, Ashby, Pollatsek, \& Reichle, 2004; Drieghe, Rayner, \& Pollatsek, 2005; Pollatsek, Rayner, \& Balota, 1986; Kliegl \& Engbert, 2005; Rayner, Juhasz, Ashby, \& Clifton, 2003) have found inflated fixations ${ }^{6}$, while others (Engbert, Longtin, \& Kliegl, 2002; Radach \& Heller,

${ }^{3}$ SWIFT perhaps does a better job than E-Z Reader with respect to accounting for the frequency of regressions, but neither model does particularly well in accounting for regressions due to higher-order processes (though see Reichle, Warren, \& O'Connell, 2009)

${ }^{4}$ Indeed, a particularly compelling finding that is quite problematic for models that do not allow for early influences of lexical processing on eye movements is the disappearing text studies (Liversedge, Rayner, White, VergilinoPerez, Findlay, \& Kentridge, 2004; Rayner, Liversedge, White, \& Vergilino-Perez, 2003; Rayner, White, \& Liversedge, 2006). In these studies, on each fixation the fixated word is masked or disappears at a certain point in the fixation. As long as the reader sees the word for 50-60 ms, reading proceeds quite normally. More interesting, how long the readers' eyes remain in place is strongly influenced by the frequency of the word. Thus, although the word is no longer there, its frequency determines how long the eyes remain in place. This is striking evidence for the early influence of lexical variables on fixation times.

${ }^{5}$ SWIFT accounts for single fixation IOVP effects, while E$\mathrm{Z}$ Reader basically accounts for the first of several fixations. While the effect with single fixations has not been demonstrated using E-Z Reader, the mechanism that accounts for the IOVP effect with the first of two fixations (i.e., an automatic refixation assumption) should also produce the effect (at least to some degree) with single fixations.

${ }^{6}$ It should be noted that although Kliegl and Engbert did find inflated fixations prior to skips the data did not necessarily conform to what would be predicted by E-Z Reader. They reported that fixations before skipped words were shorter before short or high-frequency words and longer before long or low-frequency words in comparison with fixations on the same words when they were followed by fixations on the next word (i.e., when the next word was not skipped). 
2000) have not (though those that have not are often corpus based analyses). The data on this issue may be noisy due to the fact, as noted above, experimenters can't control when readers skip a word. There are also possible influences on skipping related to deliberate versus accidental (due to motor error) skips.

Second, E-Z Reader predicts that readers generally should not obtain preview benefit from word $n+2$. That is, the model predicts that in the normal course of events, readers should obtain preview benefit from the word to the right of fixation (word $n+1$ ), but not word $n+2$ (unless word $n+2$ is the target of the next saccade from word n). Again, this prediction follows from the serial architecture of E-Z Reader. For the most part, a series of studies originating with Rayner, Juhasz, and Brown (2007) have generally confirmed the prediction that there is not preview benefit for word $n+2$ (see also Angele, Slattery, Yang, Kliegl, \& Rayner, 2008; Kliegl, Risse, \& Laubrock, 2007; McDonald, 2006). SWIFT does predict that there should be preview benefit effects from word $n+2$, and it may be the case that readers can obtain preview benefit from word $n+2$ when word $\mathrm{n}$ and word $\mathrm{n}+1$ are both short, high frequency words. Such a situation could be seen as an existence proof for SWIFT, but E-Z Reader can account for the occasional preview benefit from word $n+2$ (i.e., when word $n+1$ is identified and skipped). Overall, the general pattern of results on experiments dealing with the lack of preview benefit for word $n+2$ might suggest that SWIFT can best handle the results if it is assumed that much of the time the model is acting like E-Z Reader (or an SAS type model).

Third, SWIFT predicts that there should be parafoveal-on-foveal effects wherein the characteristics of word $n+1$ influence the amount of time that readers look at word n. According to E-Z Reader, parafovealon-foveal effects should be limited to orthographic effects, and there should not be lexical effects. Thus, the frequency of word $n+1$ should not influence the amount of time that readers look at word $n$ according to E-Z Reader, whereas it should according to SWIFT. The entire issue of parafoveal-on-foveal effects is highly contentious (see Rayner \& Juhasz, 2004; Rayner, White, Kambe, Miller, \& Liversedge, 2003 for reviews). In alphabetic writing systems, lexical parafoveal-on-foveal effects are typically not found via the boundary paradigm, though there are exceptions (i.e., Kliegl et al., 2007 reported a parafoveal-on-foveal effect). On the other hand, parafoveal-on-foveal effects are routinely reported for corpus analyses of eye movements in reading (Kennedy \& Pynte, 2005; Kliegl, Nuthmann, \& Engbert, 2006; see Kliegl, 2007; Rayner, Pollatsek, Drieghe, Slattery, \& Reichle, 2007 for further discussion). Compared to preview benefit effects, parafoveal-on-foveal effects tend to be weak and the direction of the effect is not consistent across studies 7 It should also be noted that the lack of semantic preview benefit effects is problematic for SWIFT.
In E-Z Reader, parafoveal-on-foveal effects are generally explained in terms of mislocated fixations (Drieghe, Rayner, \& Pollatsek, 2007; Rayner, Warren, Juhasz, \& Liversedge, 2004). That is, due to noise in either the oculomotor system or the eyetracking equipment, where the eyes are fixating and where attention is (or more specifically, which word was actually being processed) could be in different places. Thus, for example, due to undershoot in the oculomotor system, the eyes could be on word $\mathrm{n}$ while attention (and hence word processing) is on word $n+1$. Such a mislocated fixation account would explain many parafoveal-onfoveal effects. It is quite interesting that Nuthmann, Engbert, and Kliegl (2005) have used modeling techniques to convincingly demonstrate the frequency with which mislocated fixations occur, but they (as proponents of the SWIFT model) do not consider mislocated fixations to be the main cause of parafoveal-on-foveal effects.

A final prediction comes from an observation that Reingold (2003) generated concerning E-Z Reader. He noted that experimental manipulations that disrupt early encoding of visual and orthographic features of the fixated word without affecting subsequent lexical processing should influence the processing difficulty of the fixated word without affecting the processing of the next word. Reingold and Rayner (2006) then explicitly tested this prediction and found results consistent with E-Z Reader.

One could compute a score card of how well empirical studies support the predictions of E-Z Reader versus SWIFT. In doing so, it may be that beauty is in the eye of the beholder. My goal in this section has not really been to provide a scorecard, but rather to document some of the predictions the models make. Perhaps the most unbiased statement that could be made is that each model has support, but that there are problems with extant data for each model as well. But, more importantly, my guess is that many experiments that have been reported over the past few years would not have been done had it not been for the explicit predictions made by the models. To this extent, the models have been extremely important in driving forward empirical work in the field of eye movements and reading.

\footnotetext{
${ }^{7}$ Interestingly, Yang, Wang, Xu, and Rayner (2009) recently reported a parafoveal-on-foveal effect with Chinese, suggestion that readers of Chinese obtain some information of the word to the right of the fixation that influences the current fixation duration. And, Yan, Richter, Shu, and Kliegl (2009) recently reported semantic preview benefit effects for Chinese. It may be that such differences are due to the fact that any given Chinese character in a word will be closer to fixation on average than letters within words in English. Thus, there is much more possibility that semantic preview benefit effects and parafoveal-on-foveal effects may occur in a character based written language like Chinese than in an alphabetic horizontally spatially extended language like English.
} 


\section{Explaining Counterintuitive Findings}

An interesting finding recently emerged in our laboratory; we found that gaze durations on a noun were longer when the preceding adjective was low frequency than when it was high frequency but were actually shorter when the adjective was long than when it was short (Pollatsek, Juhasz, Reichle, Machacek, \& Rayner, 2009). This counterintuitive finding is one that caused us to shake our heads in frustration for some time, but when we actually implemented a simulation of the experiment using E-Z Reader, we found that the model accounted for the data. Likewise, Nuthmann, Engbert, and Kliegl (2007) compellingly documented how the counterintuitive IOVP effect mentioned above emerged in SWIFT simulations.

My point in this section is that computational models can be very informative, not only with respect to generating interesting predictions for researchers to test, but they can also sometimes account for otherwise seemingly unexplainable findings that might emerge from empirical investigations. Thus, the models can sometimes offer researchers assistance in accounting for interesting and counterintuitive findings.

\section{Changes to the Models}

An interesting issue with respect to the development of models is the extent to which any given model should be changed as a result of convincing evidence that is inconsistent with original assumptions of the model. Some purists might consider it a cheat to make changes to a model once it has been presented. Indeed, charges of a model being a moving target are often made when the model is changed. Yet, it seems quite rational that a given model would be changed when there are data that emerge that the architects of the model deem valid. For example, results reported by Rayner, Ashby et al. (2004) resulted in a change to E-Z Reader. An original assumption in E$Z$ Reader was that frequency and predictability share a multiplicative function. However, data from Rayner, Ashby et al. (2004) found additive (or weakly interactive) effects of frequency and predictability in an experiment in which the two variables were orthogonally varied. Thus, the equation relating frequency and predictability was changed to an additive function to account for the data pattern (see also Miellet, Sparrow, \& Sereno, 2007). It is also worth noting that changes have been made to SWIFT as a result of empirical data that emerged. Thus, the original version of SWIFT (Engbert et al. 2002) differs from the current version (Engbert et al., 2005) and the changes were implemented as a result of data deemed to be in conflict with the original version. Such changes seem to be entirely appropriate and valid.

\section{Extending the Models}

As noted earlier, E-Z Reader has been extended to older readers and to Chinese readers. Research has demonstrated that elderly readers make longer fixation durations, shorter saccades, but skip words more often and regress back to those words more often than younger readers (Laubrock, Kliegl, \& Engbert, 2006; Rayner, Castelhano, \& Yang, 2009; Rayner, Reichle, Stroud, Williams, \& Pollatsek, 2006). Such effects have been modeled in the context of both E-Z Reader (Rayner et al., 2006) and SWIFT (Laubrock et al., 2006). Also, a considerable amount of recent research has examined the characteristics of eye movements of Chinese readers. And, E-Z Reader has been extended to account for these data (Rayner, Li, \& Pollatsek, 2007).

\section{The Role of Models and Data}

It should hopefully be apparent that models of eye movement control in reading have successfully accounted for much of the important available data. But, it is important to realize that the models can only be tested via good experiments. Thus, the models and good data go hand in hand in advancing the field. Although we are now in a fourth era of eye movement research in reading where the models have been admittedly quite dominant (for reasons discussed above) one shouldn't lose sight of the fact that there should always be an important role for empirical data. Furthermore, the models are not perfect and there are aspects of the eye movement record that they do not do a particularly good job of capturing, such as regressions (Mitchell, Shen, Green, \& Hodgson, 2008), and the effect of higher order influences on fixation times (see Reichle et al., 2009).

For the most controversial aspects of eye movements during reading, such as (1) parafoveal-on-foveal effects, (2) word skipping, and (3) regressions, there seems to be a division between experimental studies and corpus-based studies. While it is clearly the case that corpus-based analyses are best suited for certain issues, such corpus-based studies are being increasingly used in cases where experimental control is quite possible. Experimenters in the field need to ask themselves which empirical approach to data acquisition should be trusted more? There isn't always a simple answer to this question (cf., Kliegl et al., 2006; Kliegl, 2007; Rayner et al., 2007), but one thing is certain and that is data obtained via corpus-based analyses need to be confirmed via experimental studies, and vice versa.

As a caveat, let me note the following. I often read papers submitted to journals (and sometimes in print) saying: These data provide evidence against E$Z$ Reader or SWIFT. In my opinion, this is not a wise statement! It would be more accurate to say that the data are not consistent with the model as currently implemented. In many cases where it is argued that the 
data are inconsistent with the model, it is simply the case that the model hasn't tried to account for the data. And, you can't know if the model doesn't account for an effect until you do the simulation (e.g., see Pollatsek et al., 2006). Fortunately, in the case of both E-Z Reader and SWIFT, the models are publicly available (along with information on how to use the $\operatorname{cod} \mathrm{e}^{8}$, and thus researchers other than the architects of the model can use them to run simulations and thereby generate/test predictions (see Miellet et al., 2007 for an example). In part, the issue here is that some researchers have adopted the practice of making "predictions" about the models based on their (sometimes faulty) understanding of the model, run experiments that provide results that are inconsistent with the "predictions", and then conclude that the model has been falsified. In such situations, the predictions aren't really valid to begin with because the experimenters have not done what needs to be donenamely, that the novel prediction needs to be derived and tested from the model. Basically, this amounts to researchers making claims about what the model can or cannot do without first checking to see if such claims are true.

Another issue has to do with how models of eye movement control are tested against each other. Three points are relevant. First, as discussed above, there is a well established set of benchmark phenomena that all of the serious researchers involved with eye movement control models have adopted and use in model evaluation. Second, while it might be argued that it would be desirable to have a fixed test suite of corpora for model evaluation, the fact that several different corpora (and not just one corpus) are being used in model evaluation can be seen as a strength, and not a weakness of the modeling endeavor. For example, this allows researchers to evaluate model generalizability across writing systems and languages. Finally, cross-validation procedures have been explicitly used in some cases (see McDonald, Carpenter, \& Shillcock, 2005), and rough equivalents of such procedures (e.g., using the same model and parameter values to fit data from completely independent experiments) have also been widely used (e.g., Rayner et al., 2005).

Finally, it is worth noting that there are now a number of models of eye movement control in scene perception and visual search that have appeared recently (see Rayner, 2009). However, these models focus primarily on where we move our eyes and say little about when we move our eyes. In general, work on eye movements in scene perception and visual search has lagged behind work in reading. This is not surprising since with reading the stimulus characteristics are easier to specify and the task is more apparent. However, the future looks promising with respect to models of eye movement control in scene perception/visual search, and hopefully architects of these models will soon move towards explaining not only where viewers move their eyes in scene perception and reading, but also attempt to explain the when decision with respect to moving the eyes.

\section{Summary}

Models of eye movement control in reading have stimulated a lot of research. While these models have, in some sense, dominated the field recently, there is still an important place for well-designed experiments and empirical data. The models and data should go handin-hand in furthering our understanding of reading.

\section{References}

Altarriba, J., Kambe, G., Pollatsek, A., \& Rayner, K. (2001). Semantic codes are not used in integrating information across eye fixations in reading: Evidence from fluent Spanish-English bilinguals. Perception E Psychophysics, 63, 875-890.

Angele, B., Slattery, T.J., Yang, J., Kliegl, R., \& Rayner, K. (2008). Parafoveal processing in reading: Manipulating $\mathrm{n}+1$ and $\mathrm{n}+2$ previews simultaneously. Visual Cognition, 16, 697-707.

Buswell, G.T. (1935). How people look at pictures. Chicago: University of Chicago Press.

Drieghe, D., Rayner, K., \& Pollatsek, A. (2005). Eye movements and word skipping during reading revisited. Journal of Experimental Psychology: Human Perception and Performance, 31, 954-969.

Drieghe, D., Rayner, K., \& Pollatsek, A. (2008). Mislocated fixations can account for parafoveal-onfoveal effects in eye movements during reading. Quarterly Journal of Experimental Psychology, 61, 1239-1249.

Engbert, R., Longtin, A., \& Kliegl, R. (2002). A dynamical model of saccade generation in reading based on spatially distributed lexical processing. Vision Research, 42, 621-636.

Engbert, R., Nuthmann, A., Richter, E., \& Kliegl, R. (2005). SWIFT: A dynamical model of saccade generation during reading. Psychological Review, $112,777-813$.

Feng, G. (2006). Eye movements as time-series random variables: A stochastic model of eye movement control in reading. Cognitive Systems Research, 7, 70-95.

${ }^{8}$ See the following URL for E-Z Reader:

http://www.pitt.edu/ reichle/ezreader.html and for SWIFT see: http://www.agnld.uni-potsdam.de/ ralf/ swift/ 
Huey, E.B. (1908). The psychology and pedagogy of reading. New York: Macmillan.

Just, M.A., \& Carpenter, P.A. (1980). A theory of reading: From eye fixations to comprehension. Psychological Review, 87, 329-354.

Kennedy, A, \& Pynte J. (2005). Parafoveal-on-foveal effects in normal reading Vision Research, 45, 153168.

Kennedy, A., \& Pynte, J. (2008). The consequences of violations to reading order: An eye movement analysis. Vision Research, 48, 2309-2320.

Kliegl, R. (2007). Toward a perceptual-span theory of distributed processing in reading: A Reply to Rayner, Pollatsek, Drieghe, Slattery, and Reichle (2007). Journal of Experimental Psychology: General, $136,530-537$.

Kliegl, R., \& Engbert, R. (2005). Fixation durations before word skipping in reading. Psychonomic Bulletin E Review, 12, 132-138.

Kliegl, R., Nuthmann, A., \& Engbert, R. (2006). Tracking the mind during reading: The influence of past, present, and future words on fixation durations. Journal of Experimental Psychology: General, 135, 12-35.

Kliegl, R., Risse, S., \& Laubrock, J. (2007). Preview benefit and parafoveal-on-foveal effects from word $\mathrm{n}+2$. Journal of Experimental Psychology: Human Perception and Performance, 33, 1250-1255.

Laubrock, J., Kliegl, R., \& Engbet, R. (2006). SWIFT explorations of age differences in eye movements during reading. Neuroscience and Biobehavioral Reviews, 30, 872-884.

Legge, G.E., Hooven, T.A., Klitz, T.S., Mansfield, J.S., \& Tjan, B.S. (2002). Mr. Chips 2002: New insights from an ideal-observer model of reading. Vision Research, 42, 2219-2234

Legge, G.W., Klitz, T.S., \& Tjan, B.S. (1997). Mr. Chips: An ideal-observer model of reading. Psychological Review, 104, 524-553.

Liversedge, S.P., Rayner, K., White, S.J., VergilinoPerez, D., Findlay, J.M., \& Kentridge, R.W. (2004). Eye movements while reading disappearing text: Is there a gap effect in reading? Vision Research, 44, 1013-1024.

McConkie, G.W., Kerr, P.W., Reddix, M.D., \& Zola, D. (1988). Eye movement control during reading: I.
The location of initial fixations in words. Vision Reseach, 28, 1107-1118.

McConkie, G. W., \& Rayner, K. (1975). The span of the effective stimulus during a fixation in reading. Perception \& Psychophysics, 17, 578586.

McDonald, S.A. (2006). Parafoveal preview benefit in reading is only obtained from the saccade goal. Vision Research, 46, 4416-4424.

McDonald, S.A., Carpenter, R.H.S., \& Shillcock, R.C. (2005). An anatomically-constrained, stochastic model of eye movement control in reading. Psychological Review, 112, 814-840.

Mitchell, D.C., She, X., Green, M.J., \& Hodgson, T.L. (2008). Accouting for regressive eye-movements in models of sentence processing: A reappraisal of the Selective Reanalysis hypothesis. Journal of Memory and Language, 59, 266-293.

Miellet, S., Sparrow, L., \& Sereno, S.C. (2007). Word frequency and predictability effects in reading French: An evaluation of the E-Z Reader model. Psychonomic Bulletin \& Review, 14, 762-769.

Nuthmann, A., Engbert, R., \& Kliegl, R. (2005). Mislocated fixations during reading and the inverted optimal viewing position effect. Vision Research, $45,2201-2217$

Pollatsek, A., Juhasz, B.J., Reichle, E.D., Machacek, D., \& Rayner, K. (2008). Immediate and delayed effects of word frequency and word length on eye movements during reading: A reversed delayed effect of word length. Journal of Experimental Psychology: Human Perception and Performance, 34, 726-750.

Pollatsek, A., Rayner, K., \& Balota, D. A. (1986). Inferences about eye movement control from the perceptual span in reading. Perception $\mathcal{E}$ Psychophysics, 40, 123-130.

Pollatsek, A., Reichle, E.D., \& Rayner, K. (2006). Tests of the E-Z Reader model: Exploring the interface between cognition and eye movements. Cognitive Psychology, 52, 1-56.

Radach, R., \& Heller, D. (2000). Relations between spatial and temporal aspects of eye movement control. In A. Kennedy, R.Radach, D. Heller, and J. Pynte (Eds.), Reading as a perceptual process (pp. 169-192). Oxford, UK: Elsevier.

Rayner, K. (1975). The perceptual span and peripheral cues during reading. Cognitive Psychology, 7, 65-81. 
Rayner, K. (1978). Eye movements in reading and information processing. Psychological Bulletin, 85, 618660.

Rayner, K. (1979). Eye guidance in reading: Fixation locations in words. Perception, 8, 2130.

Rayner, K. (1998). Eye movements in reading and information processing: 20 years of research. Psychological Bulletin, 124, 372-422.

Rayner, K. (2009). Eye movements and attention in reading, scene perception, and visual search. Quarterly Journal of Experimental Psychology, in press.

Rayner, K., Ashby, J., Pollatsek, A., \& Reichle, E.D. (2004). The effects of frequency and predictability on eye fixations in reading: Implications for the E-Z Reader model. Journal of Experimental Psychology: Human Perception and Performance, 30, 720-732.

Rayner, K., Balota, D. A., \& Pollatsek, A. (1986). Against parafoveal semantic preprocessing during eye fixations in reading. Canadian Journal of Psychology, 40, 473-483.

Rayner, K., Castelhano, M.S., \& Yang, J. (2009). Eye movements and the perceptual span in older and younger readers. Psychology and Aging, in press.

Rayner, K., \& Juhasz, B.J. (2004). Eye movements in reading: Old questions and new directions. European Journal of Cognitive Psychology, 16, 340352.

Rayner, K., Juhasz, B.J., Ashby, J. \& Clifton, C. (2003). Inhibition of saccade return in reading. Vision Research, 43, 1027-1034.

Rayner, K., Juhasz, B.J., \& Brown, S.J. (2007). Do readers obtain preview benefit from word $n+2$ ? A test of serial attention shift versus distributed lexical processing models of eye movement control in reading. Journal of Experimental Psychology: Human Perception and Performance, 33, 230-245.

Rayner, K., Li, X., \& Pollatsek, A. (2007). Extending the E-Z Reader model of eye movement control to Chinese readers. Cognitive Science, 31, 1021-1034.

Rayner, K., Liversedge, S.P., \& White, S.J. (2006). Eye movements when reading disappearing text: The importance of the word to the right of fixation. Vision Research, 46, 310-323.
Rayner, K., Liversedge, S.P., White, S.J., \& VergilinoPerez, D. (2003). Reading disappearing text: Cognitive control of eye movements. Psychological Science, 14, 385-389.

Rayner, K., Pollatsek, A., Drieghe, D., Slattery, T.J., \& Reichle, E.D. (2007). Tracking the mind during reading via eye movements: Comments on Kliegl, Nuthmann, and Engbert (2006). Journal of Experimental Psychology: General, 136, 520-529.

Rayner, K., Pollatsek, A., Liversedge, S.P., \& Reichle, E.D. (2009). Eye movements and non-canonical reading: Comments on Kennedy and Pynte (2008). Vision Research, in press.

Rayner, K., Reichle, E.D., Stroud, M.J., Williams, C.C. \& Pollatsek, A. (2006). The effect of word frequency, word predictability, and font difficulty on the eye movements of young and older readers. Psychology and Aging, 21, 448-465.

Rayner, K., Warren, T., Juhasz, B.J., \& Liversedge, S.P. (2004). The effect of plausibility on eye movements in reading. Journal of Experimental Psychology: Learning, Memory, and Cognition, 30, 1290-1301.

Rayner, K., White, S.J., Kambe, G., Miller, B., \& Liversedge, S.P. On the processing of meaning from parafoveal vision during eye fixations in reading. In J. Hyona, R.Radach, \& H.Deubel (Eds), The mind's eye: Cognitive and applied aspects of eye movements (pp. 213-234). Oxford: Elsevier.

Reder, S.M. (1973). On-line monitoring of eye position signals in contingent and noncontingent paradigms. Behavior Research Methods and Instrumentation, 5, 218-228.

Reichle, E.D., Liversedge, S.P., Pollatsek, A., \& Rayner, K. (2009). Encoding multiple words simultaneously in reading is implausible. Trends in Cognitive Science, in press.

Reichle, E.D., Pollatsek, A., Fisher, D.L., \& Rayner, K. (1998). Toward a model of eye movement control in reading. Psychological Review, 105, 125-157.

Reichle, E.D., Rayner, K., \& Pollatsek, A. (2003). The E-Z Reader model of eye-movement control in reading: Comparisons to other models. Behavioral and Brain Sciences, 26, 445-476.

Reichle, E.D., Warren, T., \& McConnell, K. (2009). Using E-Z Reader to model the effects of higherlevel language processing on eye movements during reading. Psychonomic Bulletin \& Review, 16, 
$1-21$.

Reilly, R., \& Radach, R. (2006). Some empirical tests of an interactive activation model of eye movement control in reading. Cognitive Systems Research, 7, 34-55.

Reingold, E.M. (2003). Eye-movement control in reading: Models and predictions. Behavioral and Brain Sciences, 26, 500-501.

Reingold, E.M., \& Rayner, K. (2006). Examining the word identification stages hypothesized by the EZ Reader model. Psychological Science, 17, 742-746.

Salvucci, D.D. (2001). An integrated model of eye movements and visual encoding. Cognitive Systems Research, 1, 201-220.

Thibadeau, R., Just, M. A., \& Carpenter, P.A. (1980). A model of the time course and content of human reading. Cognitive Science, 6, 101-155.

Tinker, M.A. (1946). The study of eye movements in reading. Psychological Bulletin, 43, 93-120.

Tinker, M.A. (1958). Recent studies of eye movements in reading. Psychological Bulletin, 55, 215-231.
Vitu, F., McConkie, G.W., Kerr, P., \& O'Regan, J.K. (2001). Fixation location effects on fixation durations during reading: an inverted optimal viewing position effect. Vision Research, 41, 35133533.

Yan, M., Richter, E., Shu, H., \& Kliegl, R. (2009). Readers of Chinese extract semantic information from parafoveal words. Psychonomic Bulletin $\mathcal{E}$ Review, in press.

Yang, J., Wang, S., Xu, Y., \& Rayner, K. (2009). Do Chinese readers obtain preview benefit from word $\mathrm{n}+2$ ? Evidence from eye movements. Journal of Experimental Psychology: Human Perception and Performance, in press.

Yang, S. (2006). A oculomotor-based model of eye movements in reading: The competition/activation model. Cognitive Systems Research, 7, 56-69.

Yang, S., \& McConkie, G.W. (2001). Eye movements during reading: a theory of saccade initiation times. Vision Research, 41, 3567-3585. 